\title{
Adaptive Body Support System for Aircraft Seat
}

\author{
CheeFai Tan", a, Matthias Rauterberg ${ }^{2}$, Wei Chen², V.K. Kher ${ }^{1}$ \\ ${ }^{1}$ Integrated Design Research Group (IDeA), Faculty of Mechanical Engineering, \\ Universiti Teknikal Malaysia Melaka, Melaka, Malaysia \\ ${ }^{2}$ Designed Intelligence Group, Department of Industrial Design, \\ Eindhoven University of Technology, Eindhoven, the Netherlands \\ acheefai@utem.edu.my
}

Keywords: Adaptive system, passenger, economy class aircraft seat.

\begin{abstract}
The development of new technology enables the comfort service becoming an important requirement in the air travel industry. Long haul air travel may cause different physiological and psychological discomfort of aircraft passenger. Most of the aircraft company treats the passenger comfort as a main priority for the user's acceptance of their airline. In order to improve the aircraft passenger body comfort during long haul air travel, an adaptive body support system was developed and embedded in the economy class aircraft seat. In this paper, we describe the development of adaptive body support system.
\end{abstract}

\section{Introduction}

Today, low cost air travel is possible and accessible for many people. Passengers from different age groups and disabilities are able to enjoy the air travel. During the journey that involving air travel, the stress and anxiety may cause the health problems due to the road traffic to the airport and unfamiliarity with airport departure. During the flight, the problems may arise from the cabin crew services, cabin environmental conditions (noise, vibration, pressure, and ventilation), cabin humidity, seat position, sitting posture and changes in time zones [1]. The long haul air travel is not a natural activity for human. Aircraft passengers may experience different level of physiological and psychological discomfort during the flight. The over stress passenger may react aggressively, over reaction and may threaten passenger health $[2,3]$.

The air travel comfort is greatly required by aircraft passengers. The aircraft passengers depend on limited features and environment to improve their own comfort during air travel. Seat comfort is a subjective issue because it is the customer who makes the comfort perception. The aircraft passenger will evaluate the seat based on their experience and opinions with the seat throughout their air travel [4]. The aircraft passenger seat is one of the elements that are important to fulfill the aircraft passenger comfort expectations.

The aircraft seat is the place where the aircraft passenger spends most of their time. The aircraft seat is used for sitting, resting, sleeping, entertaining, having meal as well as socializing with others passengers. The current economy class aircraft seat is a passive system where the passenger needs to do the adjustment manually. In the survey on seating comfort and discomfort [5], we also found that neck support is one of the top ranking comfort descriptors for economy class aircraft seat. The observation in the economy class aircraft cabin also indicates that most observed passengers preferred sitting posture with head facing forward. The head facing forward is the most comfortable head position [6]. In this paper, we describe the modeling of the developed adaptive body support system for aircraft seat.

\section{Current Body Support}

From the product search using web services, several neck supports related products were found. There are different types of neck supports that are used during air travel such as inflatable neck pillow [7], polyester filled pillow [7], memory foam pillow [7], feather filled pillow [8] and the aircraft seat with mechanical neck support [9-10]. 
Long-distance coach services, e.g. express buses, are transporting passengers from city to city and serve as main commuter for towns without any railway service [11]. The coach passenger seat is one of the important items to ensure the comfort of the long distance travel passenger. For example, an express coach that travels from Singapore to Thailand was equipped with neck, side and leg support for their passenger's comfort during long distance bus travel.

\section{The Adaptive Body Support System Architecture}

The architecture of the adaptive body support system is shown in Figure 1. Both sides of the upper part of the aircraft passenger seat are embedded with air pressure sensors. The sensors are used to detect the passenger's posture. The input parameter to the smart control module is the analog value from the air pressure sensor and the potentiometer. The output parameter is the analog value from the smart control module used to control the proportional solenoid valve. The proportional solenoid valve is used to control the air flow to and from the airbag. The smart control module is the core component of the system where it is used to mediate between sensors and actuators. The air pressure detection model is the main component in the smart control module. The database is used to record the airbag pressure as well as to provide input to the smart control module. The output from the system is the actuators.

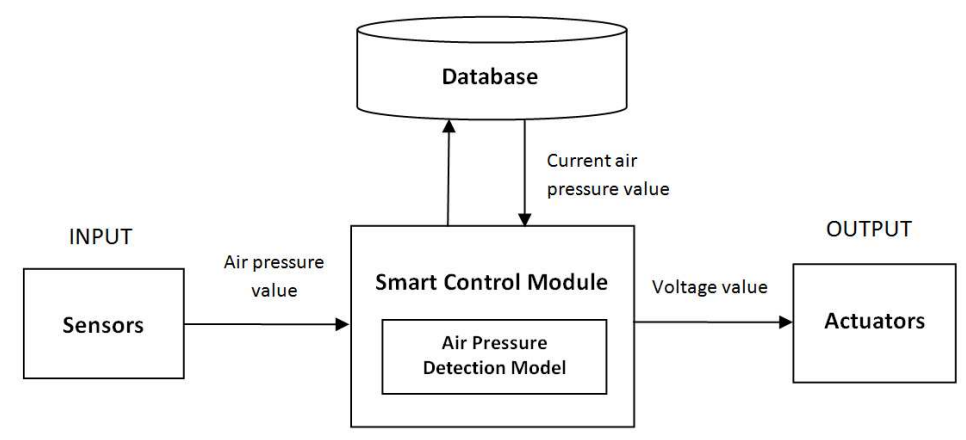

Fig. 1 The architecture of adaptive neck support system

\section{The Aircraft Seat Air-Pressure Detection Model}

The air-pressure detection model was developed to support the aircraft passenger body adaptively. The developed model is used to detect the aircraft passenger's body position by using state-of-the-art airbag system. The air pressure differences in the airbag are depends on the passenger's body position as well as sitting posture. The model records the air pressure change in the airbags. The model can be modified to take into account any variation in the air pressure. For example, if the passenger's body is away from the supported airbag, the current air pressure in the airbag will be reset.

Let,

$P_{\text {current }}=$ current air pressure in the airbag

$P_{\text {recorded }}=$ recorded air pressure when passenger is in touch with the airbag

$n_{1} \quad=$ value for upper threshold

$n_{2} \quad=$ value for lower threshold defined as

$P_{\text {airbag }}$ is the difference between the recorded air pressure and the current air pressure. $P_{\text {airbag }}$ is

$P_{\text {airbag }}=P_{\text {recorded }}-P_{\text {current }}$

$P_{\text {airbag }}$ is used for data logging purpose. 
Mathematically,

When passenger is in touch with the airbag,

$P_{\text {current }}<P_{\text {recorded }}+n_{1} \& \& P_{\text {current }}>P_{\text {recorded }}-n_{2}$

: comparing the airbag pressure

If the current air pressure in the airbag is within the defined upper threshold and the lower threshold, the adaptive neck support system is activated.

When passenger is away from the airbag that supports the neck,

$P_{\text {current }}<P_{\text {recorded }}$

: comparing the airbag pressure

The current air pressure in the airbag will decrease to a value that is less than the recorded air pressure when the head is not in touch with airbag. Hence the system can infer that passenger's head has left the airbag and deactivate the adaptive neck support system. The algorithm of air pressure detection model for the right airbag and the left airbag is shown in Figure 2.

\section{Conclusion}

In this paper, we have presented the modeling of the adaptive body support system to improve the body comfort during long haul air travel. The architecture of adaptive body support system described the system structure which consists of sensor, actuator, database and central processor. The air pressure detection model is related to the airbag system. The air pressure detection model is used for the implementation of adaptive body support system, where the airbag is capable to detect the passenger's head posture and support the passenger's neck adaptively. Next, mechanical model was developed to predict the behavior of the airbag system.

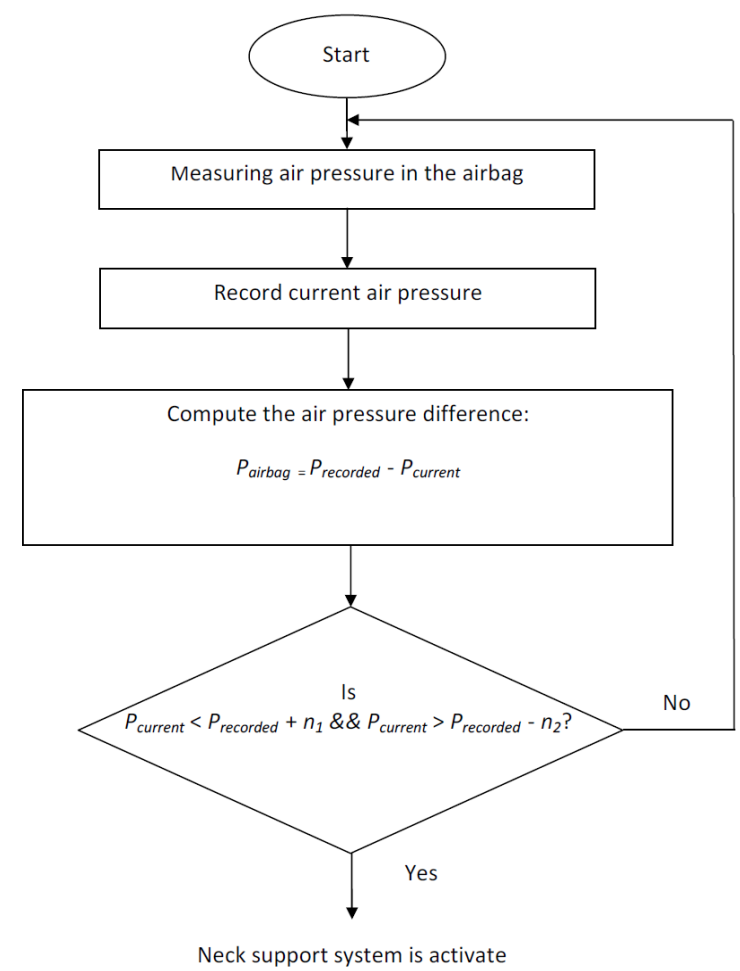

Fig. 2 The algorithm of air pressure detection model (photo reprinted from [5]) 


\section{Acknowledgements}

This work was financially supported by Ministry of Higher Education Malaysia research grant. Special thanks to the Centre of Research and Innovation Management and Faculty of Mechanical Engineering, Universiti Teknikal Malaysia Melaka for the support.

\section{References}

[1] G. Brundrett, Comfort and health in commercial aircraft: a literature review, The Journal of The Royal Society for the Promotion of Health, vol. 121 (2001), no. 1, p. 29-37

[2] S. Kalogeropoulos, Sky rage, Flight Safety Australia, pp. 36-37 (1998)

[3] World Health Organization, Travel by air: health considerations, Information on http://whqlibdoc. who.int/publications/2005/9241580364_chap2.pdf(2007)

[4] V.A. Runkle, Benchmarking seat comfort, SAE Technical Paper, No. 940217 (1994)

[5] C.F. Tan, Smart system for aircraft passenger neck support, PhD Thesis, Eindhoven University of Technology (2010)

[6] A.R. Tilley and H. Dreyfuss, The measure of man and woman: human factors in design, John Wiley \& Sons Inc., New York, (2002)

[7] Pilot Paul, It's a shame for you not to use a travel neck pillow to help you sleep while traveling when other people do it so easily, Information on http://www.pilot-pauls-travel-accessories.com/ travel-neck-pillow.html, (2010)

[8] N. Robinson, Feather Pillows- Advantages and Disadvantages You Should Know, Information on http://ezinearticles.com/?Feather-Pillows---Advantages-and-Disadvantages-You-Should Know\&id $=1122787$ (2010)

[9] Cathay Pacific, Your guide to the economy class seat, Information on http://downloads.cathaypacific.com/cx/new_seat/seatguide/Olympus_y.pdf (2010)

[10] Qantas, Qantas A380 awards, Information on http://www.qantas.com.au/travel/ airlines/ economy-seat-award/global/en (2010)

[11] D. Van de Velde, Long distance bus services in Europe: concession or free market, Discussion paper no. 2009-21, Joint Transport Research Centre, (2009)

[12] Five Star Tours, Information on http://www.fivestarsonline. com/ ?q=en/coach. (2010) 